\title{
E-Business Readiness of the SMEs in Jordan
}

\author{
Arafat A. Awajan ${ }^{1}$, Hasan Al-Shalabi ${ }^{2}$, Al-Bara W. Awajan ${ }^{3}$, Nidhal El-Omari ${ }^{4}$ \\ ${ }^{1}$ Computer Science Department, Princess Sumaya University for Technology, Amman - Jordan \\ awajan@psut.edu.jo \\ ${ }^{2}$ Computer Engineering Department, Al-Hussein Bin Talal University, Ma'an - Jordan \\ ${ }^{3}$ Computer Engineering Department. Al-Balqa' Applied University, Salt - Jordan \\ ${ }^{4}$ The World Islamic Sciences \& Education University, Amman - Jordan
}

\begin{abstract}
This paper presents the main findings of a survey conducted to evaluate the e-business readiness of small and medium enterprises in Jordan. A questionnaire was administered in the late 2011 to 200 SME operating in different economical sectors in the country. The survey aimed at analyzing the e-business readiness of these organizations by exploring three levels of analysis: the status of the ICT infrastructure, a general assessment of ICT competencies in businesses, an analysis of needs for training and an evaluation of the maturity of the market and the surrounded environment. The results show that the ICT, mainly used for administrative and commercial purposes, is considered as an investment. Its budget is allocated most of the time towards upgrading, creating new services and maintenance. They suggest a strong adoption of basic ICT, such as personnel computers, Internet access, and Web site. Exploitation of these technologies has been marked by the improvements in work organization, time saving and cost reduction. However, most of the SMEs faced problems in training employees, implementation costs and lack of maturity of the market. At the national level, the results show that more maturity is needed in the technical, business, and legal infrastructure.
\end{abstract}

\section{Indexing terms/Keywords}

Information Technology, e-Business, Jordan, Small and Medium Enterprises, e-Readiness

\section{Academic Discipline And Sub-Disciplines}

Electronic Business, E- Commerece, Information Technology

\section{SUBJECT CLASSIFICATION}

Business, management and IT Classification

\section{TYPE (METHOD/APPROACH)}

Quantative analysis; Literary Analysis; Survey and interview

\section{Council for Innovative Research}

Peer Review Research Publishing System

Journal: International Journal of Management \& Information Technology

Vol.4, No.3

editor@cirworld.com

www.cirworld.com, member.cirworld.com 


\section{INTRODUCTION}

Electronic business has become a major issue in economic policy agendas around the world and most organizations recognize the importance of the Internet and other information and communication technologies (ICT) to their future. In fact, no organization including the small and medium sized enterprises can afford to ignore these technologies and their impacts on their businesses. In Jordan as well as in many other developing countries, small and medium enterprises face numerous difficulties related to the use information and communication technologies in their various activities. These problems are mainly due to the cost, the lack of necessary infrastructure and shortage of competencies.

Michael Taylor, Andrew Murphy in (Taylor and Murphy 2004) presented a range of issues surrounding the adoption of ICT and e-business technologies and techniques by small and medium-sized enterprises (SMEs). They examined the different models of e-business adoption by SMEs as well as the barriers to the adoption of e-business technologies and techniques. They found that the main factors that promote successful adoption are related to human capital. It is concluded that the take-up of e-business by SMEs needs to be seen as a means to an end and not an end in itself.

E-readiness is relatively a new concept in the developing countries. It has been given impulsion by the rapid rate of Internet penetration throughout the world, and the dramatic advances in the use of ICT in business and industry. In the literature, the term E-business readiness has different definitions. It could be defined as the degree of preparation of a nation or community organizations to participate in and benefit from the information and communication new technologies and their developments. In the 2007 e-readiness rankings report published by the Economist Intelligence Unit written in collaboration with IBM Institute for Business Value, the E-readiness is defined as the "state of play" of a country's information and communications technology (ICT) infrastructure and the ability of its consumers, businesses and governments to use ICT to their benefit (E.I. Unit 2007). Different tools and metrics were proposed in the literature to measure the level of e-readiness in a country or market. These measurements are including qualitative and quantative measurements aiming at describing the status of different parameters affecting the penetration of e-business (S.M. Mutula, P. van Brakel 2006).

A country e-business readiness is essentially a measure of its e-business environment and its ability to support the use of ICT in its different business activities. It consists of a collection of factors that indicates how a market can take advantage from the Internet-based opportunities. It is measured in terms of different factors such as the available information and ICT infrastructures, the enterprise management abilities to deal with new trends and technologies, the human resources competencies and skills, and the readiness of the environmental factors including the maturity of the market, economical situation, the legal environment and the social factors. [Fig. 1]

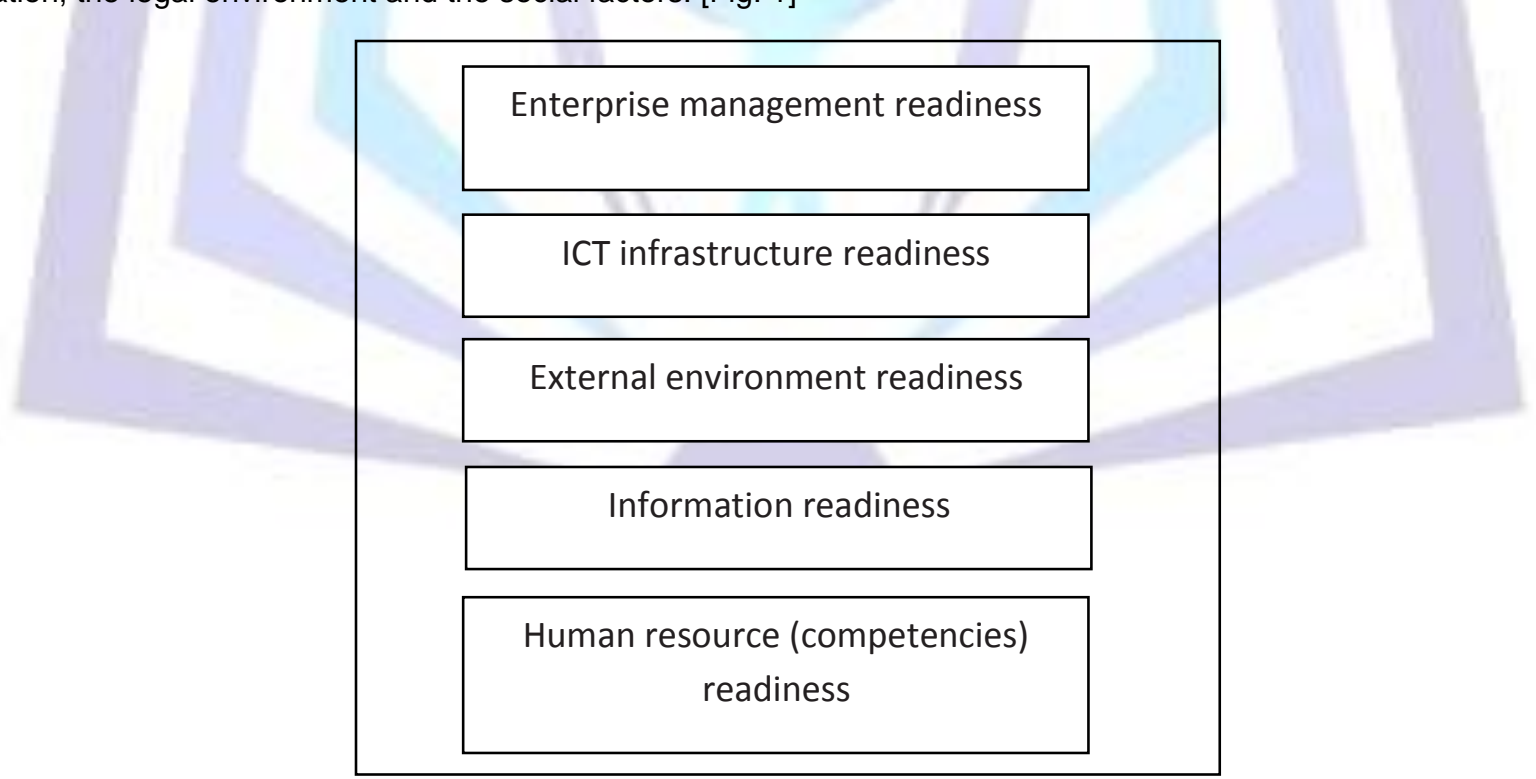

Fig 1: E-business Readiness Components

The main purpose of the study presented in this paper, is to assess the e-business readiness of the Jordanian economy namely the current situation and penetration of ICT in the different economical sectors in general and in the small and medium enterprises in particular. It aims also at obtaining a better understanding of what the fast penetration of the internet; e-business and the new ICT technologies have meant for the SME in a developing economy herein Jordan. Another focus of the study is to examine what are the main needs of the SME in terms of competencies and training, and how the universities and vocational training centers can meet these needs. 
This paper presents the methodology and the survey results. It is structured as follows. After introducing the work and representing the context of the survey in section 2, section 3 presents the methodology adopted in this study including the main components of the questionnaire and an overview of the sample of SME concerned by the survey. Section 4 reports the main results organized in term of ICT and e-business status, competencies status and training needs. In section 5 , we discuss the state of SME e-business readiness as well as addressing different challenges facing the implementation of $e$ business solutions in the SME.

\section{BACKGROUND}

Jordan is a small developing country in the Middle East region with a population of about 6.5 million. Despite the rapid growth of the usage of internet and the information and communication technologies in the world, the E-business activities are still minimal and slowly emerging in Jordan and most of the developing countries.

The world's overall e-readiness is improving perceptibly; the world's overall e-readiness is improving perceptibly, however: a global average score of 6.02 in 2006 rose to 6.24 in 2007 on a scale of 1 to 10 . According to the micro-index ranking in e-Commerce, Jordan was placed 51 st in the world. In the e-readiness ranking reports conducted by the Economist Intelligence Unit, Jordan passed from the rank 54 in 2006 to the rank 50 in 2009 with a score passed from 4.22 (of 10) in 2006 to 4.92 in 2009. Jordan is placed 4th in the region of the Middle East scored at 4.42 (of 10) after Israel, United Arab Emirates and Turkey (The Economist Intelligence Unit 2007, 2008, 2010, Jordan MICT 2006, 2011)

In 2005, a similar study has been conducted in Jordan during the implementation of the MEDFORIST project which was one of the European Union supported project within the framework EUMEDIS projects. MEDFORICT project was concerned by the implementation of a Euro-Mediterranean network for sharing learning and training resources related to the implementation of e-business solutions. Within this framework, a survey on competencies and training has been conducted in Jordan and 11 other countries from the Mediterranean region and the results are published (Medforst 2005). Six years later, we thought that it is important to analyze the situation and determine the main changes and orientation as well as to depict the main trends. A new questionnaire is designed based on that used in the first study with more focus on the small and medium enterprises in Jordan. A team of researchers from different Jordanian universities located in different regions was formed in order to have a general view describing the actual situation of ICT and the e-readiness of Jordanian organizations. This paper presents the main results of our study.

\section{METODOLOGY}

The primary goal of the SME survey was to find out information that would contribute toward the evaluation of the ebusiness readiness of the SME in Jordan. This evaluation aims mainly at helping in the successful design, development, and delivery of training materials for the SME and their employees. Both the questionnaire and the sampling methodology were designed to provide a broad view of Jordanian SME situations by assessing the working environment and the extent of the ICT and e-business tools adoption, attitudes toward the implementation of e-solutions, needs in competencies and difficulties.

\subsection{The Questionnaire:}

A 50-question survey that investigated each dimensions of e-business readiness is designed. A number of questions were adaptations of questions from the questionnaire developed during the participation of Princess Sumaya University of Technology in the MEDFORICT EU funded project (Medforst 2005).

The survey consists of five parts [Fig. 2]. The first part entitled the identification of the organization, its structure and the individual respondent. It is used to capture the relevant demographic information about the company and the individual respondent: industrial sector, size of company, managerial level and age of respondent. Part 2 is dedicated to depict the educational and training level of the staff of the organization and to assess their ability to use the new technologies in order to evaluate the human resources e-readiness including their ability to use effectively and efficiently the new technology and their resistance to introduce these technologies. The ICT level of the organization and its e-business technology readiness is the subject of the third part. Questions about the hardware and software used in the organization as well as the internet use and the presence of e-solutions and websites as well as their impacts on the organization are included in this section. The fourth part of the survey aims at determining the main needs in training the staff in addition to evaluating the training policies and practices of the organization. The last part consists of 10 questions aiming at evaluating the external environment and its impact on the readiness of the firm.

\subsection{The Sample:}

The questionnaire was administered in 2011 to over 200 small and medium enterprises operating in different economical sectors in Jordan. The collection of responses was done mainly through e-mails. In some cases, we felt the need to face- 
to-face and phone interview methods especially for completing some responses. We got 145 replies representing various activities and economic sectors.

The organizations represented in this survey were mainly small ones: $52 \%$ have fewer than 50 employees, $19 \%$ have 50 100 employees and $22 \%$ of them have $100-500$ employees [Figure 3]. The majority of these organizations are located in the capital of Jordan (Amman) and its surrounded area (77\%), and serving mainly the Jordanian and Middle-East markets (65\% and $63 \%$, respectively).

1. Identification of the organization and the individual respondent.
a. Activities - Sector
b. Size
c. Managerial level and age of individual

2. ICT Readiness (Human resources)
a. Level of Management perception of the ICT and their role
b. education (technical, business, ...)
c. Ability to use ICT (Internet, emails, word processing, ...)
d. Competencies

3. ICT Readiness (Technological Infrastructures)
a. Computers and software used
b. Main ICT applications used in the organization
c. Internet infrastructure
d. Role of websites, type and depth of services offered via Web

4. Assessment of Needs in Training
a. Main needs of training
b. Challenges: cost, time, ...
c. Availability of in-house training programs
d. Availability of the appropriate training programs

5. Legal, social and cultural environment

a. Level of maturity of national infrastructure

b. Evaluation of the legal environment

c. Perceived level of support from public sector services.

Fig 2: Survey questionnaire categories and sub-categories.

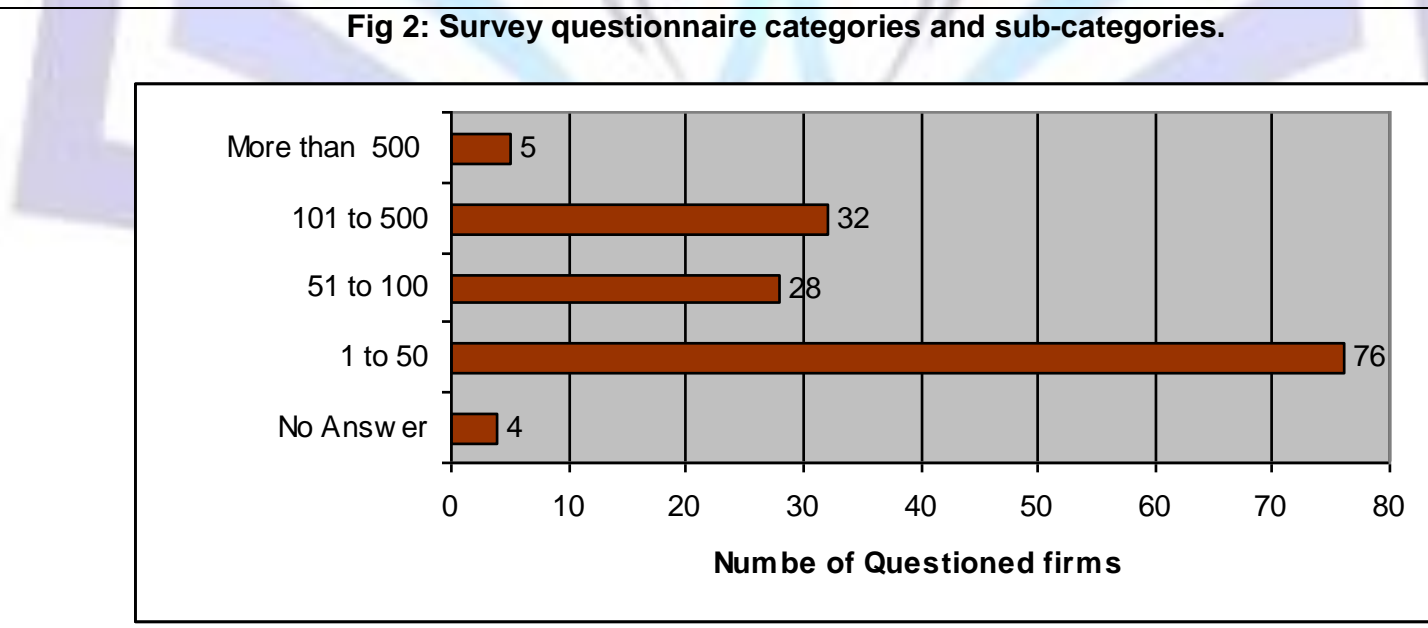

Fig 3: Number of employees

The sampling covered the main economical sectors and represented the main activities. Figure 4 shows that $23 \%$ of the organizations investigated are from the information technology sector, 17\% of organizations are from the Hotels and the tourism sector, organizations from the Banking-finance-Insurance sector represent $11 \%$ of the sample, the transport and the Health sectors each represent $5 \%$, the Industrial and Educational sectors each represent $6 \%$ of investigated organizations. The Telecom sector represents $2 \%$ of the sample. Commerce sector represents $10 \%$. Around $15 \%$ of 
organizations are from other various services and sectors. It has been noticed that most of the filled questionnaires came from the most developed and more internationally connected sectors.

\section{SURVEY RESULTS}

The majority of surveyed SMEs have active use of e-mail to reach efficient communications with customers, partners and supplier. They start always by building and publishing a website. Once the business is engaged in marketing, selling or buying online, it starts to analyze their situation, implement their own e-business strategy and develop a business model that transforms it into an increasingly virtual and networked organisation.

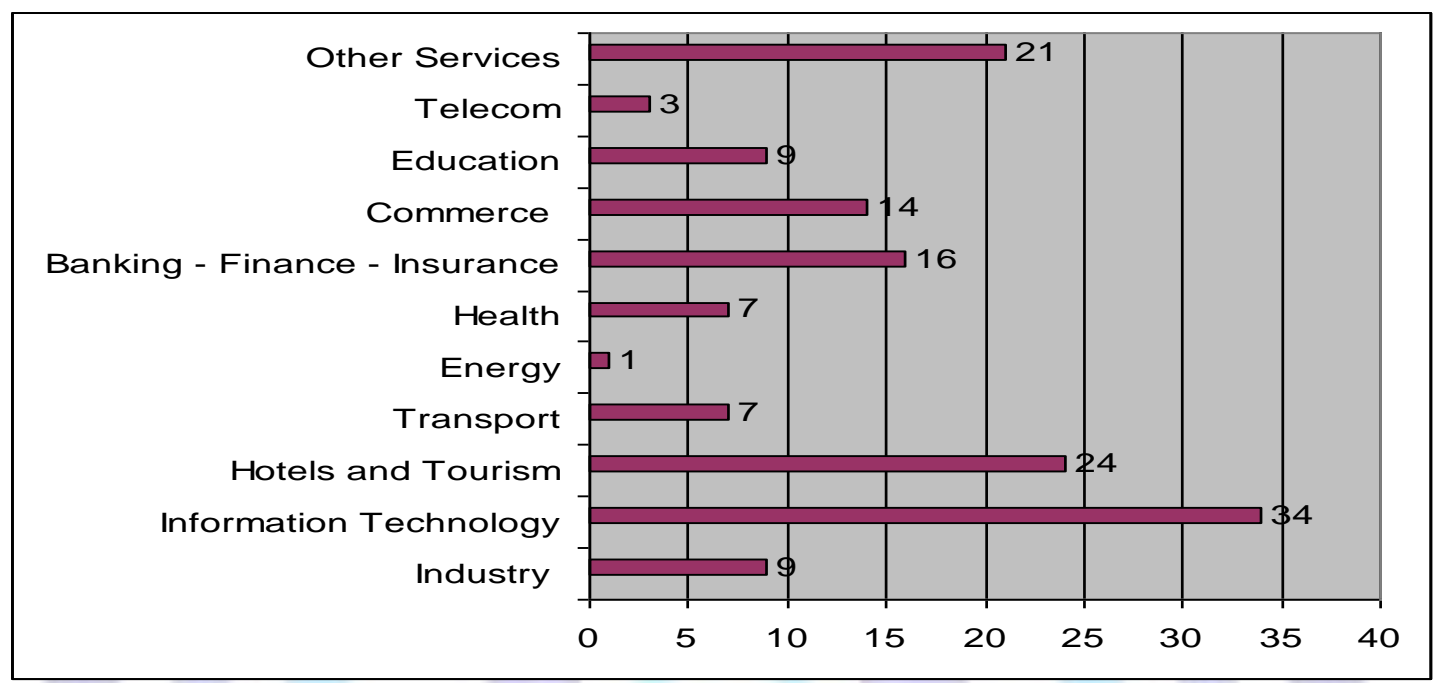

Fig 4: Economical Sector

\subsection{Status of the ICT infrastructure}

This section will be focusing on the ICT infrastructure that facilitates conducting e-Business activities within the organization. The ICT infrastructure and human resources at any organization are the most basic means of determining the organization's own perception of the significance of e-business and its commitment to a more efficient usage of IT.

The survey includes questions aiming at evaluating the ICT infrastructures readiness by measuring the level and the type of the ICT used by the Jordanian SME as well as at identifying the main uses and impacts of these technologies. The assessment of the infrastructure involves the extent of the existence of the core infrastructure of the information and communication technologies and the extent of their access and availability, affordability, quality and reliability, and security. The Penetration (numbers), allocated budget and the usage of ICT infrastructure in conducting the main activities of the business are the main factors considered in this part of the study.

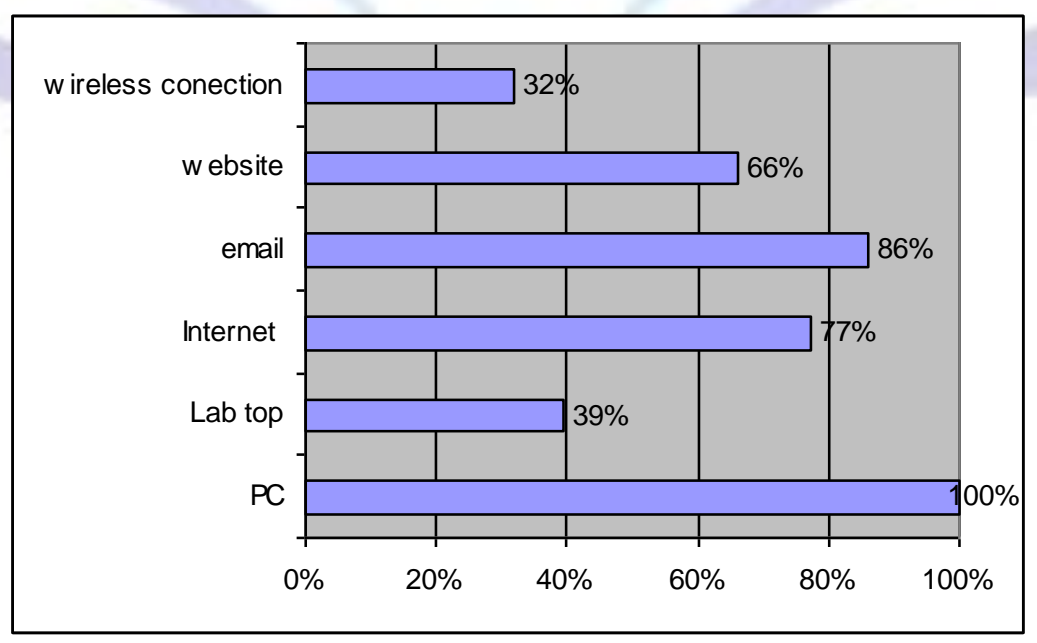

Fig 5: ICT Infrastructure Penetration 
The use of personal computers (100\%), e-mail (86\%) and the Internet $(77 \%)$ is high by the firms included in this survey. Workplace access to basic ICTs needed for conducting e-business is correspondingly high, with access in the $70-100 \%$ range. Sixty-six percent of organizations reported having their own web site. The Web site existence is generally limited to the biggest companies working mainly in most developed sectors namely the ICT, education, banking and tourism. The use of lab top (39\%) and wireless technologies (32\%) is limited mainly for security reasons. [Figure 5]

The budget allocated for ICT infrastructure and applications in investigated organizations is mostly allocated for new services, new products, up-grading existing systems, and for maintenance purposes. 55\% of organizations consider spending money on ICT as an investment rather than a cost seen by $33 \%$ of the organizations. Although the cost of a personal computer can be as low as $\$ 400$, this is still seen an expensive price for the majority of the smallest SMEs in the country. The development of the cellular phone industry has provided a viable alternative especially to provide the organization a cheaper mean for the e-marketing activities and for some organization to shop online. These new technologies are seen as providing an economically viable solution for mass e-commerce adopters.

\subsection{Human resources and Competencies status}

Jordan's labour pool is well educated, and the ICT education is a top national priority (Ranking in Quality of education: 37 in the world) which can be seen as a good resources to develop the e-activities. The results show that the educational level of employees in the majority of organizations is of high school degree or professional colleges degree, followed by stuff with employees with first university degree level, while stuff with vocational education and/or higher degree also exists, which depends on the type of organizations [Fig. 6]. Also results have indicated that $65 \%$ of organizations offer training for their employees, majority of organizations offer training for existing and newly hired employees, $71.7 \%$ of them offer training whenever need arises, $13.2 \%$ offer yearly training for their stuff, while $9.1 \%$ train their stuff on a monthly basis, and $6.1 \%$ on a quarterly basis. Qualified staff are also been trained in some organizations, while unqualified staff hold the lowest percent.

As for the impact on the jobs inside the organization, it was observed in most organization that the ICT adoption was an opportunity for job creation, although ICT adoption was the reason for some job suppression in some sectors.

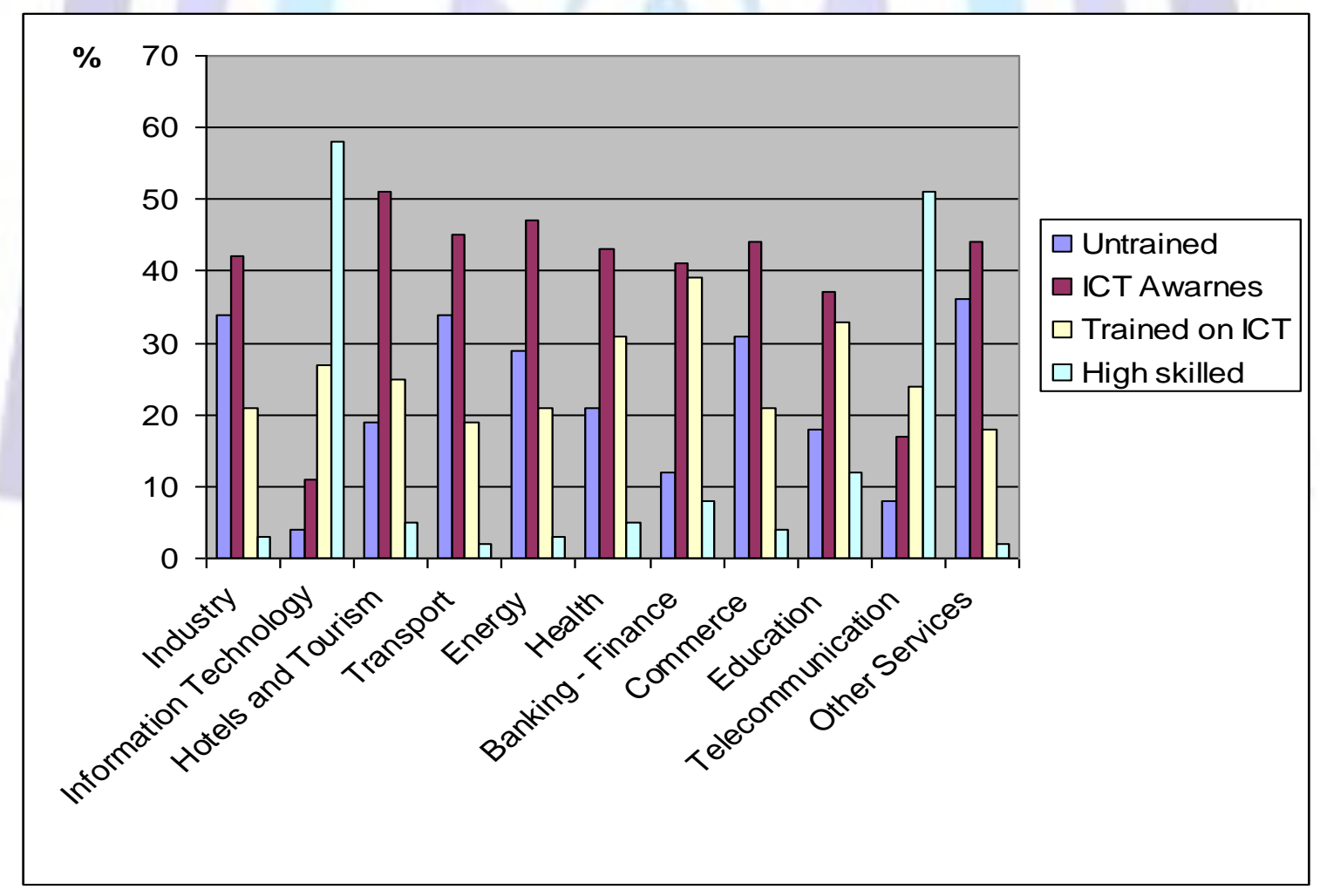

Fig 6: ICT Competencies Status of Staff

\subsection{Training needs}

Most of organizations look for local markets, local universities and high school graduate when they recruit new staff especially for the vacancies related to the new technologies. They would like to see their needs satisfied through the local 
labor market. The last note is very important to be satisfied by the national universities and vocational centers. On the one hand, universities should stress on "Masters degree" programs oriented towards the e-business and on the other hand, firms should be ready to elaborate training sessions to update their human resources knowledge in the field.

As for the needs in training concerning the ICT, it seems that these needs are in all aspects of ICT: operating e-systems, using Internet services and facilities, leading e-business projects or designing and maintaining dynamic sites. The survey shows that most of organizations need staff for managerial positions mainly. And, in the technical positions, the needs are mostly for E-project managers, database administrator and information system administrator, which are, as we notice, at a high level of competency.

The level of perception of the importance of using ICTs in management is a step higher for medium sized firms. Almost $90 \%$ rated it as at least important. In practice, medium firms use ICTs mostly for financial and administrative purposes, as well human resources. Like for small firms, there is a need for medium sized firms to extend the use of ICTs to other components of management (e.g. order processing and follow up, internal and external communication). Like small firms, medium firms ranked "unqualified personnel" as the number one barrier to using ICTs in management (about $35 \%$ of firms).

\subsection{Environmental factors}

The organization's interaction with external entities like the customers, suppliers, government and competitors is considered by $74.5 \%$ of organization as a critical issue that encourages or discourages the organization engagement in ebusiness. Concerning the relationship with the public sector, $66.7 \%$ have different levels of relationships with the public sector, and 33.3\% had no such relations. Policy changes, political forces and government intervention can have significant ramifications for e-business development.

In Jordan as well as in other developing countries, technology infrastructure is directly related to the regulatory systems and administrative policies. Low levels of investment and limited sources of financing are seen by $67.6 \%$ of the study sample as the primary reasons for the slow development of e-business. With public and private funds lacking for infrastructure development, even broadly available technologies remain too costly for widespread adoption.

\section{CONCLUSION}

This study was an effort aiming at assessing the current state of the e-Business readiness of small and medium enterprises in Jordan. The potential opportunities and barriers to SMEs usage of ICT are also analyzed. The results allowed us to assess the ability of the country to promote and support digital business and information and communications technology (ICT) services. Most of the surveyed companies recognize the importance of the Internet and other electronic technologies to their future. In addition, we found that all sectors are interested in using the ICT and introducing e-business tools in their activities.

From the different findings of this study, we can conclude that the majority of SMEs in Jordan was not found as close to being e-ready even though they have good accessibility to the ICT infrastructures. However, extending e-readiness to include the use, awareness and barriers to ICTs, one may conclude that e-readiness is in general proportional to size, and hence larger firms are the most e-ready.

\section{REFERENCES}

[1] Michael Taylor, Andrew Murphy (2004). SMEs and e-business Journal of Small Business and Enterprise Development Volume: Vol. 11. No. 3.

[2] The Economist Intelligence Unit 2007. The 2007 e-readiness rankings: A white paper from the Economist Intelligence Unit written in collaboration with IBM Institute for Business Value. Accessed 10 November 2012 at http://graphics.eiu.com/files/ad_pdfs/2007Ereadiness_Ranking_WP.pdf

[3] Stephen M. Mutula, Pieter van Brakel (2006). An evaluation of e-readiness assessment tools with respect to information access: Towards an integrated information rich tool. International Journal of Information Management 26 (2006) 212-223

[4] The Economist Intelligence Unit 2008. E-readiness rankings 2008 - Maintaining momentum: A white paper from the Economist Intelligence Unit written in collaboration with IBM Institute for Business Value. Accessed 10 November 2012 at http://graphics.eiu.com/upload/ibm_ereadiness_2008.pdf

[5] The Economist Intelligence Unit 2010. Digital economy rankings 2010 - Beyond e-readiness: A report from the Economist Intelligence Unit written in collaboration with IBM Institute for Business Value. Accessed 10 November 2012. http://www-935.ibm.com/services/us/gbs/bus/html/ibv-digitaleconomy2010.html.

[6] Jordan MICT 2006. The e-Readiness Assessment of the Hashemite Kingdom of Jordan: A report published by the Jordanian Ministry of ICT and the Information and Communication Technology Association - Jordan 
[7] Jordan MICT 2011. ICT and ITES Industry Statistics 2011: A report published by the Jordanian Ministry of ICT and the Information and Communication Technology Association - Jordan. http://www.intaj.net/content/2010-it-and-itesindustry-statistics. Accessed on 10 February 2013.

[8] Medforist 2005. EUMEDIS-Strand 2 - MEDFORIST - N528 - Euro-Mediterranean Network for sharing IST learning resources. Internal Report of the MEDFORIST Project, Deliverable D15, 2005. 